\title{
Effect of exercise training on total daily physical activity in elderly humans.
}

Citation for published version (APA):

Meijer, E. P., \& Westerterp, K. R. (1999). Effect of exercise training on total daily physical activity in elderly humans. European Journal of Applied Physiology and Occupational Physiology, 80(1), 16-21.

https://doi.org/10.1007/s004210050552

Document status and date:

Published: 01/01/1999

DOI:

10.1007/s004210050552

Document Version:

Publisher's PDF, also known as Version of record

Document license:

Taverne

Please check the document version of this publication:

- A submitted manuscript is the version of the article upon submission and before peer-review. There can be important differences between the submitted version and the official published version of record.

People interested in the research are advised to contact the author for the final version of the publication, or visit the DOI to the publisher's website.

- The final author version and the galley proof are versions of the publication after peer review.

- The final published version features the final layout of the paper including the volume, issue and page numbers.

Link to publication

\footnotetext{
General rights rights.

- You may freely distribute the URL identifying the publication in the public portal. please follow below link for the End User Agreement:

www.umlib.nl/taverne-license

Take down policy

If you believe that this document breaches copyright please contact us at:

repository@maastrichtuniversity.nl

providing details and we will investigate your claim.
}

Copyright and moral rights for the publications made accessible in the public portal are retained by the authors and/or other copyright owners and it is a condition of accessing publications that users recognise and abide by the legal requirements associated with these

- Users may download and print one copy of any publication from the public portal for the purpose of private study or research.

- You may not further distribute the material or use it for any profit-making activity or commercial gain

If the publication is distributed under the terms of Article $25 \mathrm{fa}$ of the Dutch Copyright Act, indicated by the "Taverne" license above, 


\section{Effect of exercise training on total daily physical activity in elderly humans}

\begin{abstract}
This study examined the effect of 12 weeks of exercise training on daily physical activity in elderly humans. Training consisted of a weekly group session and an individual session with cardio- and weight-stack machines. A group of 15 subjects served as the exercise group [EXER mean age 59 (SD 4) years], and 7 subjects as the controls [CONT mean age 57 (SD 3) years]. Physical activity and physical fitness were measured before the start of training (T), at week 6 and week 12 $\left(T_{0}, T_{6}, T_{12}\right.$ respectively) in EXER, and at $T_{0}$ and $T_{12}$ in CONT. Physical activity over 14 days was measured using a tri-axial accelerometer and physical fitness was measured during an incremental exercise test. At $T_{12}$, mean maximal power output had significantly increased in EXER compared to CONT 8 (SD 12) vs -5 (SD 9) $\mathrm{W} ; P<0.02]$ and mean submaximal heart rate (at $100 \mathrm{~W}$ ) had reduced [-10 (SD 7) vs -2 (SD 6) beats $\left.\min ^{-1} ; P<0.05\right]$. No differences or changes in physical activity were observed between EXER and CONT. At $\mathrm{T}_{6}$, physical activity on training days was significantly higher than on non-training days $(P<0.001)$. When the accelerometer output of the training session was subtracted from the accelerometer output on training days, at $\mathrm{T}_{12}$ non-training physical activity was significantly lower than on non-training days $(P<0.004)$. Accelerometer output of the individual training session at $\mathrm{T}_{12}$ had significantly increased compared to $\mathrm{T}_{6}$ $(P<0.05)$, whereas, accelerometer output of the group training session had remained unchanged. In conclusion,
\end{abstract}

E.P. Meijer $(\bowtie) \cdot$ K.R. Westerterp

Department of Human Biology,

Maastricht University,

P.O. Box 616, NL-6200 MD,

Maastricht, The Netherlands

F.T.J. Verstappen

Department of Movement Sciences,

Maastricht University,

P.O. Box 616, NL-6200 MD,

Maastricht,

The Netherlands in elderly subjects an exercise training programme of moderate intensity resulted in an improved physical fitness but had no effect on total daily physical activity. Training activity was compensated for by a decrease in non-training physical activity.

Key words Physical activity · Exercise training . Accelerometer $\cdot$ Physical fitness

\section{Introduction}

Aging is frequently associated with a decrease in physical activity and consequently a decline in physical fitness, which may lead to a vicious circle of less and less physical activity and declining physical fitness. It has been suggested that the level of physical activity might, also, influence the decrease in fat-free mass with age (Rising et al. 1994; Horber et al. 1996; Van Pelt et al. 1997). Therefore, exercise programmes for the elderly have been developed to improve or maintain strength, muscle mass and physical fitness. Studies with young adults have shown that exercise intervention programmes can influence body composition, energy metabolism and physical fitness in a beneficial way (Meijer et al. 1991b; Poehlman et al. 1992; Van Etten et al. 1997).

Westerterp (1998) reviewed five studies on the effect of a training programme on averaged daily metabolic rate (ADMR) measured using the doubly labelled water method (Bingham et al. 1989; Blaak et al. 1992; Goran and Poehlman 1992; Westerterp et al. 1992; Van Etten et al. 1997), one of which was in children, three in young adults and one in the elderly. The energy expenditure associated with non-training physical activity was calculated from the difference between ADMR and resting metabolic rate after adjusting for the thermic response to feeding and the energy cost of the exercise training. In children and young adults the size of the change in energy expenditure associated with physical activity was on average twice the energy cost of the exercise training 
intervention programme. However, in the elderly subjects it was found that the endurance training programme did not change total energy expenditure. Here, it was suggested that the intensity of the training programme was too high, resulting in a decline in nontraining physical activity (Goran and Poehlman 1992).

The doubly labelled water method, however, can only be used to quantify the average level of physical activity over intervals of 1-3 weeks and does not provide information about patterns of physical activity related to time. Assessment of physical activity patterns in subjects by using body-fixed accelerometers seems to offer promising possibilities. Bouten et al. (1994) developed a tri-axial accelerometer based on three separate uni-axial accelerometers. Comparison between physical activity generated accelerometer output and activity associated energy expenditure as measured using the doubly labelled water method in 30 free-living subjects over 7-day intervals has shown a significant relationship $(r=0.79$; Bouten et al. 1996). Meijer et al. (1991a) and Van Etten et al. (1997) have measured non-training physical activity with a tri-axial accelerometer before training, and at 8 and 18-20 weeks of an exercise training programme in young adults and found no change in non-training physical activity.

The purpose of this study was to investigate the effect of a 12-week exercise training programme of moderate intensity on the daily physical activity in elderly humans. Physical activity was measured by using a tri-axial accelerometer.

\section{Methods}

\section{Subjects}

The subjects were recruited from advertisements in the local media. Selection criteria were: age over 55 years, no health problems and no participation in sports during the previous year. Detailed information concerning the purpose and methods used in the study was provided, and written consent was obtained. The study was approved by the Ethics Committee of Maastricht University. A group of 15 subjects ( 8 women, 7 men) participated in the exercisetrained group (EXER), and 7 subjects ( 4 women, 3 men) served as non-trained controls (CONT). The variables comprising body composition, basal metabolic rate (BMR), daily physical activity and physical fitness were measured at training $(\mathrm{T})$ week $\mathrm{T}_{0}$ (baseline), at $\mathrm{T}_{6}$ (6 weeks of training) and $\mathrm{T}_{12}$ (12 weeks of training) in EXER and at $\mathrm{T}_{0}$ and $\mathrm{T}_{12}$ in CONT.

\section{Body composition}

Physical characteristics are shown in Table 1. Anthropometric measurements were taken after an overnight stay at the laboratory. After voiding, body mass was measured on an electronic scale (Mettler, E1200). Body volume was determined by weighing underwater. Residual lung volume was simultaneously measured using the helium dilution technique (Volugraph 2000, Mijnhardt). Total body water (TBW) was determined using deuterium $\left({ }^{2} \mathrm{H}_{2} \mathrm{O}\right)$ dilution. Body composition was calculated from body mass, body volume and TBW using the three-compartment model of Siri (1956).
Table 1 Characteristics of the exercise (EXER), and control group $(C O N T)$. There were no differences between the groups

\begin{tabular}{lcccc}
\hline & EXER & \multicolumn{3}{c}{ CONT } \\
\hline Number (men, women) & $15(7,8)$ & & $7(3,4)$ \\
& mean & SD & mean & SD \\
Age (year) & 58.9 & 3.5 & 57.4 & 2.6 \\
Body mass (kg) & 71.4 & 10.1 & 70.0 & 9.4 \\
Height (m) & 1.67 & 0.07 & 1.67 & 0.08 \\
Body mass index $\left(\mathrm{kg} \cdot \mathrm{m}^{2}\right)$ & 25.6 & 3.1 & 25.1 & 1.1 \\
Fat $(\%)$ & 32.9 & 8.8 & 33.3 & 6.9 \\
Maximal O & 2.03 & 0.5 & 1.99 & 0.5 \\
$\quad\left(1 \cdot\right.$ min $^{-1}$ ) & & & & \\
Maximal power output $(\mathrm{W})$ & 145 & 40 & 135 & 32 \\
Maximal heart rate & 163 & 13 & 159 & 18 \\
$\quad\left(\right.$ beats $\cdot$ min $^{-1}$ ) & & & & \\
\hline
\end{tabular}

Basal metabolic rate

After an overnight fast the BMR was measured for 30 min at 0700 hours. Oxygen consumption and carbon dioxide production were measured using a computerized, open-circuit, ventilated hood system. Expired gases were analysed using a paramagnetic oxygen analyser (Servomex, The Netherlands) and an infrared carbon dioxide analyser (Servomex, The Netherlands). The system was similar to the analysis system for respiration chambers which has been described previously by Schoffelen et al. (1997). Calculation of BMR was based upon the equation of Weir (1949).

\section{Daily physical activity}

Physical activity over a 14-day period was measured using a triaxial accelerometer, consisting of three uni-axial piezo-electric accelerometers, attached to the lower back of the subject by an elastic belt. It was a smaller version $(69 \times 28 \times 9 \mathrm{~mm}, 23 \mathrm{~g})$ of that used in previous studies (Bouten et al. 1994; Van Etten et al. 1997). The accelerometer calculated the sum of the rectified and integrated acceleration curves from the antero-posterior, medio-lateral and longitudinal axis of the trunk. The period for integration was set at $1 \mathrm{~min}$. The subjects were instructed to wear the accelerometer during waking hours, except during bathing and showering.

\section{Physical fitness}

To investigate the effect of the training programme on aerobic power (maximal oxygen uptake, $\dot{V} \mathrm{O}_{2 \max }$ ) and maximal power output $\left(W_{\max }\right)$, the subjects exercised incrementally on an electromagnetically braked cycle ergometer (Lode Excalibur, Groningen, The Netherlands). They started to cycle for $3 \mathrm{~min}$ at $30 \mathrm{~W}$ at 60 $\mathrm{rev} \cdot \mathrm{min}^{-1}$ and the exercise intensity was increased every minute by $10 \mathrm{~W}$ until they were exhausted. Criteria for maximal performance were a forced ventilation, a levelling off of oxygen uptake or a respiratory exchange ratio $(R)$ above 1.1 . The oxygen uptake during the test was measured continuously, using a computerized open system (SensorMedics 2900 analyser, Anaheim, Calif., USA). During the incremental exercise test heart rate was measured continuously (Polar Sport Tester, Kempele, Finland). To quantify the effect of the training programme on heart function, heart rates were compared at a power output of $100 \mathrm{~W}$.

\section{Training programme}

The subjects trained twice a week at a fitness club, once in a group session of 60 min with various aerobic exercises and once in an individual session of $90 \mathrm{~min}$ consisting of nine exercises using cardio- and weight-stack machines. Two sets of ten repetitions were performed in the following exercises: lat row, pec deck, leg 
extension, leg curl, biceps curl, triceps extension, shoulder press and sit-ups. In addition, each session included a 10-min of warming-up and cooling-down with walking or cycling at a self-selected intensity. A group session was chosen to improve compliance. The training sessions were supervised by a fitness instructor. The mean average training compliance was 85 (SD 9)\%.

\section{Statistics}

Paired Student's $t$-tests were used to examine differences in EXER between baseline measurements and $\mathrm{T}_{6}$ and $\mathrm{T}_{12}$. Due to the small size of the group non-parametric Wilcoxon signed-rank tests were used to examine differences in CONT between baseline measurements and $T_{12}$. An analysis of variance (ANOVA) for repeated measures within subjects was used to compare accelerometer output between $T_{6}$ and $T_{12}$. To compare differences between EXER and CONT, a non-parametric Mann-Whitney $U$-test was used. Statistical significance was set at $P<0.05$.

\section{Results}

\section{Body composition}

In neither group, EXER or CONT, did the subjects show any change in body mass (Table 2). There were no changes in mean body composition in EXER $\left[\mathrm{T}_{0}, \mathrm{~T}_{6}\right.$ and $\mathrm{T}_{12}$ : 33.0 (SD 8.0), 32.5 (SD 7.6) and 33.5 (SD 8.1)\% fat mass, respectively]. Mean body composition in CONT, however, changed significantly $\left[\mathrm{T}_{0}\right.$ vs $\mathrm{T}_{12}: 32.8$ (SD 5.9) vs 34.1 (SD 5.4$) \%$ fat mass; $P<0.05]$.

\section{Basal metabolic rate}

There were no changes in mean BMR in either EXER $\left[\mathrm{T}_{0}, \mathrm{~T}_{6}\right.$ and $\mathrm{T}_{12}: 4.7$ (SD 0.5), 4.7 (SD 0.5) and 4.7 (SD $0.6) \mathrm{kJ} \cdot \mathrm{min}^{-1}$, respectively] or CONT $\left[\mathrm{T}_{0}, \mathrm{~T}_{12}: 4.6(\mathrm{SD}\right.$ 0.6), $4.7(\mathrm{SD} 0.4) \mathrm{kJ} \cdot \mathrm{min}^{-1}$, respectively].

Daily physical activity

As depicted in Fig. 1, average physical activity as measured with the tri-axial accelerometer over 2-week in-

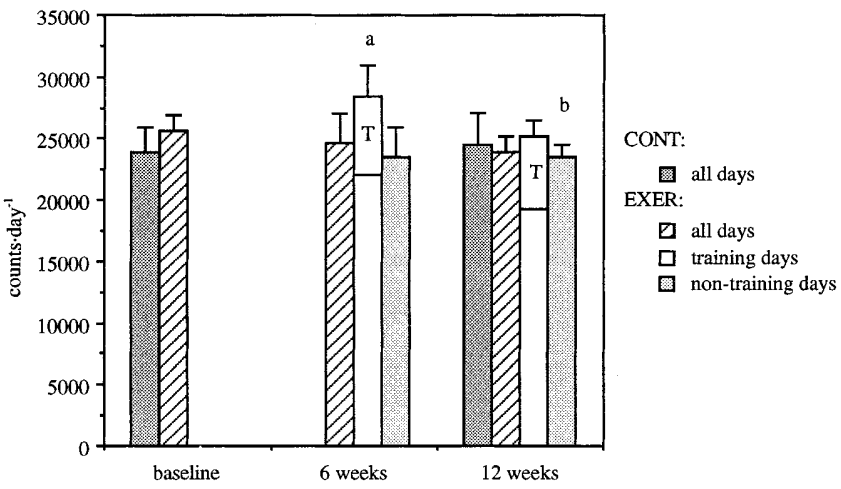

Fig. 1 Accelerometer output counts (mean and SEM) during training days and non-training days. Accelerometer output did not differ between the exercise (EXER) and control (CONT) groups. $T$ Mean counts produced during a training session. Significantly different counts between training and non-training days ${ }^{a} P<0.001$. Significantly different counts between nontraining days and training days minus training session $\left({ }^{\mathrm{b}} P<0.01\right)$

tervals did not change between $\mathrm{T}_{0}, \mathrm{~T}_{6}$ and $\mathrm{T}_{12}$ in EXER [25 572 (SD 5016), 24697 (SD 9223), 23935 (SD 5093) counts $\cdot$ day $^{-1}$, respectively] or in CONT [23990 (SD 5176), 24568 (SD 6358) counts $\cdot \mathrm{day}^{-1}$, respectively]. At $\mathrm{T}_{6}$ mean physical activity was significantly higher on training days than on non-training days [28 477 (SD 9328) vs 23482 (SD 9251) counts $\cdot$ day $^{-1} ; P<0.001$ ], whereas, at $\mathrm{T}_{12}$ the difference between mean physical activity on training days and non-training days just failed to reach significance $[25234$ (SD 4690) vs 23575 (SD 5543) counts $\cdot$ day $\left.^{-1} ; P=0.06\right]$. The difference in mean physical activity between training days and nontraining days was significantly larger at $T_{6}$ than at $T_{12}$ $\left[4996\right.$ (SD 4252) vs 1659 (SD 3529) counts $\cdot$ day $^{-1}$; $P<0.05]$.

A training session resulted in mean accelerometer outputs of 6064 (SD 1420) counts at $\mathrm{T}_{6}$ and 6949 (SD 2146) counts at $\mathrm{T}_{12},(P=0.09)$. The mean accelerometer output of the individual training session was significantly higher at $\mathrm{T}_{12}$ than at $\mathrm{T}_{6}[6925$ (SD 2110) vs 5521 (SD 1689) counts; $P<0.05$; Fig. 2], whereas, the
Table 2 Changes in body composition, basal metabolic rate and physical fitness in the exercise (EXER), and the control $(C O N T)$ groups compared to baseline. $T_{0}$ Baseline training, $T_{6}, T_{12} 6$ and 12 weeks of training

\begin{tabular}{|c|c|c|c|c|c|c|}
\hline & \multicolumn{4}{|l|}{ EXER } & \multirow{2}{*}{\multicolumn{2}{|c|}{$\frac{\mathrm{CONT}}{\mathrm{T}_{12}}$}} \\
\hline & \multicolumn{2}{|l|}{$\mathrm{T}_{6}$} & \multicolumn{2}{|l|}{$\mathrm{T}_{12}$} & & \\
\hline & mean & SEM & mean & SEM & mean & SEM \\
\hline Body mass (kg) & 0.0 & 0.3 & -0.2 & 0.3 & 0.2 & 0.4 \\
\hline Fat $(\%)$ & -0.4 & 0.3 & 0.5 & $0.4^{\mathrm{a}}$ & 1.3 & $0.4^{*}$ \\
\hline $\begin{array}{l}\text { Basal metabolic } \\
\text { rate }\left(\mathrm{kJ} \cdot \mathrm{min}^{-1}\right)\end{array}$ & 0.0 & 0.1 & 0.0 & 0.1 & 0.0 & 0.2 \\
\hline $\begin{array}{l}\text { Maximal } \mathrm{O}_{2} \text { uptake } \\
\left(1 \cdot \min ^{-1}\right)\end{array}$ & 0.09 & 0.07 & 0.10 & 0.06 & -0.17 & 0.09 \\
\hline $\begin{array}{l}\text { Maximal power } \\
\text { output (W) }\end{array}$ & 7 & $4^{*}$ & 8 & $3 * * *$ & -5 & $3^{b}$ \\
\hline $\begin{array}{l}\text { Heart rate at } 100 \mathrm{~W} \\
\left(\text { beats } \cdot \min ^{-1}\right)\end{array}$ & -8 & 1 & -10 & $2 * * *$ & -2 & $2^{b}$ \\
\hline
\end{tabular}

Significantly different from $T_{0}:{ }^{*} P<0.05$, *** $P<0.001$. Significantly different from $T_{6}$ : ${ }^{\text {a }} P<0.01$. Significantly different between the groups: ${ }^{\mathrm{b}} P<0.05$ 


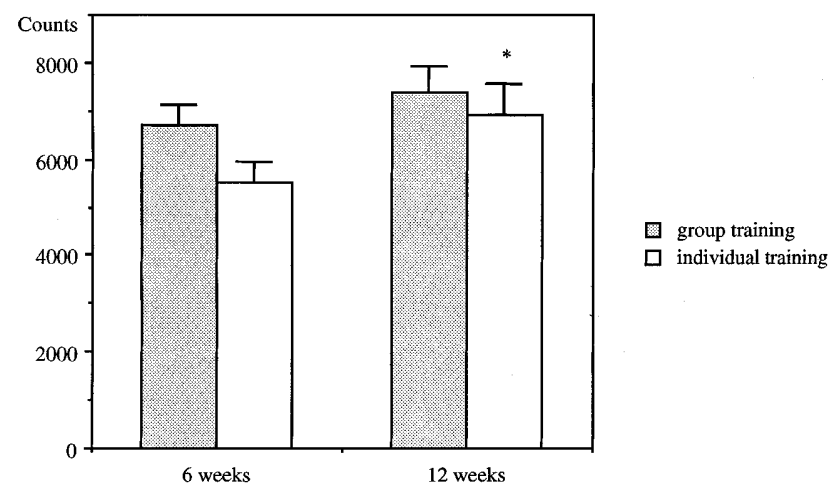

Fig. 2 Accelerometer output counts (mean and SEM) during group and individual training sessions. Significantly different from week $6 * P<0.05$

mean accelerometer output of the group training session was not significantly different between $\mathrm{T}_{12}$ and $\mathrm{T}_{6}[7389$ (SD 2547) vs 6716 (SD 1675) counts; Fig. 2]. When the accelerometer output produced during a training session was subtracted from total accelerometer output on training days, at $\mathrm{T}_{12}$ the mean physical activity on training days was significantly lower than on nontraining days [18285 (SD 4568) vs 23575 (SD 5543) counts $\cdot$ day $^{-1} ; P<0.01$; Fig. 1]. At $\mathrm{T}_{6}$ no difference was shown between mean non-training physical activity on training days when compared with that on nontraining days [22414 (SD 9095) vs 23482 (SD 9251) counts $\cdot$ day $\left.^{-1}\right]$.

\section{Physical fitness}

In Table 2 the differences in $W_{\max }$ and $\dot{V} \mathrm{O}_{2 \max }$ measured by the incremental exercise test are given for both groups. The $W_{\max }$ at $\mathrm{T}_{12}$ had increased significantly in EXER, whereas the increase in $\dot{V} \mathrm{O}_{2 \max }$ at $\mathrm{T}_{12}$ in EXER just failed to reach significance $(P=0.06)$. In CONT no significant changes in $W_{\max }$ and $\dot{V} \mathrm{O}_{2 \max }$ were found. Heart rate at $100 \mathrm{~W}$ was significantly reduced in EXER at $\mathrm{T}_{6}$ and $\mathrm{T}_{12}$ when compared with $\mathrm{T}_{0}[130$ (SD 19) and 128 (SD 22) vs 138 (SD 17) beats $\cdot \min ^{-1} ; P<0.001$ ], whereas heart rate at $100 \mathrm{~W}$ in CONT remained unchanged between $\mathrm{T}_{0}$ and $\mathrm{T}_{12}$ [135 (SD 13) vs 132 (SD 20)].

\section{Discussion}

The present study was undertaken to examine the effect of regular exercise training on daily physical activity in healthy elderly individuals. Daily physical activity was measured with a tri-axial accelerometer. The results showed that total physical activity over 14 days was not influenced by an exercise training programme of moderate intensity, which was in contrast with the findings of Meijer et al. (1991a). They have shown, in young adults, an increase in total physical activity which was almost entirely due to the extra running activity of the exercise training programme. In the present study, physical activity on training days was significantly higher than on non-training days, which was due to the imposed physical activity of the of exercise training. After subtracting the physical activity of the session of exercise training, after 12 weeks the subjects showed a significant decrease in non-training physical activity on training days (Fig. 1), a finding-training which agrees with those of Goran and Poehlman (1992). They suggested that the level of exercise during the last week of their training programme $\left(3 \mathrm{~h} \cdot\right.$ week $^{-1}$ at $85 \%$ of $\left.\dot{V} \mathrm{O}_{2 \max }\right)$ was too strenuous, and thus fatigued the elderly participants during the remainder of the day. They proposed that exercise training of lower intensity might influence the level of daily physical activity. Although a lower exercise intensity for training was used in the present study, nontraining physical activity on training days decline, which could probably be explained by the difference in exercise intensity on $T_{6}$ and $T_{12}$. At $T_{6}$ the exercise training had no influence on non-training physical activity on training days (Fig. 1). At $T_{12}$, when a higher exercise intensity was used, the elderly subjects showed a decline in nontraining physical activity on training days. It would seem that elderly subjects resist an increased exercise intensity.

The duration of the intervention might also partly explain the decline in non-training physical activity. Goran and Poehlman (1992) reported a decline in nontraining physical activity after 8 weeks of endurance training. The present study showed a decline in nontraining physical activity only after 12 weeks of training. Probably, 6 weeks of exercise training was too short a time to influence non-training physical activity.

The decline in non-training physical activity at $\mathrm{T}_{12}$ could not be attributed to the fact that the exercise training programme had fatigued the elderly participants during the remainder of the day, because the training sessions were undertaken in the afternoon. It would seem that elderly subjects anticipate exercise training by reducing their physical activity before the training sessions, possibly by resting more to save energy. The results, therefore, cannot support the suggestion of Goran and Poehlman (1992), that the elderly compensate for exercise training by reducing their physical activity afterwards. From a clinical perspective, our results would indicate that exercise prescribed for the elderly might reduce non-training physical activity.

The mean intensity of the individual training session, as measured with the tri-axial accelerometer, was significantly higher at $\mathrm{T}_{12}$ when compared with $\mathrm{T}_{6}$ (Fig. 2). The group training sessions at $\mathrm{T}_{12}$, however, were not significantly different from group training sessions at $\mathrm{T}_{6}$. Thus, the mean increase in training intensity of both training sessions taken together just failed to reach significance $(P=0.09)$. The difference between the individual and the group sessions might have been due to the differences in training intensity of the individuals. During the individual sessions the load of the cardio- and 
weight-stack machines was determined from each individual's physical fitness at the onset of training and was adjusted throughout the 12-week programme, whereas the various aerobic exercises of the group sessions were based on the mean level of physical fitness of the group.

Although the training programme decreased nontraining physical activity, a significant increase in $W_{\max }$ was observed. The $\dot{V} \mathrm{O}_{2 \max }$ tended to increase (Table 2); the $5 \%$ increase in mean $\dot{V} \mathrm{O}_{2 \max }$, although not significant, after the 12-week exercise training [2.03 (SEM 0.5) vs 2.13 (SEM 0.6$\left.) 1 \cdot \mathrm{min}^{-1} ; P=0.06\right]$ was similar to the results of previous studies (Goran and Poehlman 1992; Posner et al. 1992; Takeshima et al. 1993). Posner et al. (1992) have reported a $8.5 \%$ increase in $\dot{V} \mathrm{O}_{2 \max }$ after 16 weeks of exercise training of moderate intensity on a cycle ergometer. Goran and Poehlman (1992) used an 8week exercise training programme of high intensity and reported a significant $11 \%$ increase in $\dot{V} \mathrm{O}_{2 \max }$, which agrees with the findings of Takeshima et al. (1993), who have shown a $10 \%$ increase in $\dot{V} \mathrm{O}_{2 \max }$ after 12 weeks of endurance training at lactate threshold in elderly subjects. In elderly adults, however, it could be more important to detect improvements in the submaximal response to exercise training which have been shown to be related more to the accomplishment of daily activities (De Vito et al. 1997).

In the present study, the reduced heart rate after the 12-week training programme at a power output of $100 \mathrm{~W}$ was in agreement with findings of De Vito et al. (1997). They used an exercise training programme of low intensity with various aerobic exercises three times a week and demonstrated a significant reduction of 6 beats $\cdot \min ^{-1}$ in the post-training when compared with the pre-training heart rate. Belman and Geasser (1991) showed a training-induced reduction in heart rate of 8 beats $\cdot \min ^{-1}$ at a submaximal power output after 8 weeks of exercise training of low intensity (30 min walking at $50 \% \dot{V} \mathrm{O}_{2 \max }$ four times a week). Thus, an exercise training programme of moderate intensity twice a week as used in the present study would seem to improve physical fitness in healthy elderly adults.

The lack of a change in body mass is in accordance with other exercise training intervention studies (Bingham et al. 1989; Meijer et al. 1991b; Blaak et al. 1992; Goran and Poehlman 1992; Campbell et al. 1994; Van Etten et al. 1997). These studies, however, have shown a significant increase in fat-free mass and a decrease in fat mass. The present study started at the end of October (autumn) and was completed in February (winter). It has been suggested that body mass and body composition may show seasonal fluctuations, with an increase in body mass and fat mass in the winter and a decrease before summer (Van Staveren et al. 1986). Fat mass increased significantly in CONT, whereas no significant changes in body composition in EXER were found (Table 2). Therefore, it can be argued that the exercise training programme prevented the increase in fat mass due to seasonal changes.
The unchanged BMR in EXER, in the present study, was in accordance with other exercise training intervention studies (Bingham et al. 1989; Meijer et al. 1991b; Blaak et al. 1992; Van Etten et al. 1997; Wilmore et al. 1998). These studies have shown that there is no clear long-term effect of exercise training on BMR. Two studies with elderly persons however, have reported an increase in BMR (Goran and Poehlman 1992; Campbell et al. 1994). Campbell et al. (1994) used a 12-week resistance training programme, whereas Goran and Poehlman (1992) used an 8-week endurance training programme. Both studies measured BMR, as in the present study, at least $36 \mathrm{~h}$ after the last training session to prevent any carry-over effect from the last period of exercise and both studies reported an increased fat-free mass.

Although fat-free mass is an important determinant of BMR, most studies have shown an exercise-induced increase in fat-free mass without an increase in BMR (Bingham et al. 1989; Meijer et al. 1991b; Blaak et al. 1992; Westerterp et al. 1994; Van Etten et al. 1997). The longest training intervention study (40 weeks of endurance training) showed the biggest absolute change in fatfree mass without an increase in BMR (Westerterp et al. 1994). In contrast, after 40 weeks of endurance training BMR was slightly lower while fat-free mass was significantly increased by $5 \%$. It has been speculated that BMR may have changed as a defence mechanism of body mass maintenance, because body mass was significantly decreased by $1.0 \pm 1.7 \mathrm{~kg}$. The intensity of the training programme used in this study and the fact that there were no significant changes in body mass and body composition might explain why BMR was unchanged after 12 weeks of training.

In conclusion, in the elderly an exercise training programme of moderate intensity resulted in an increase in physical activity, which was compensated for by a decrease in non-training physical activity. The exercise training programme resulted in increased physical fitness.

Acknowledgements The authors wish to thank Loek Wouters for carrying out the deuterium dilution analyses.

\section{References}

Belman MJ, Geasser GA (1991) Exercise training below and above the lactate threshold in the elderly. Med Sci Sports Exerc 23:562-568

Bingham SA, Goldberg GR, Coward WA, Prentice AM, Cunnings JH (1989) The effect of exercise and improved physical fitness on basal metabolic rate. Br J Nutr 61:155-173

Blaak EE, Westerterp KR, Bar-Or O, Wouters LJM, Saris WHM (1992) Effect of training on total energy expenditure and spontaneous activity in obese boys. Am J Clin Nutr 55:777-782

Bouten CVC, Westerterp KR, Verduin M, Janssen JD (1994) Assessment of energy expenditure for physical activity using a triaxial accelerometer. Med Sci Sports Exerc 26:1516-1523

Bouten CVC, Verboeket-Van de Venne WPHG, Westerterp KR, Verduin M, Janssen JD (1996) Daily physical activity assessment: comparison between movement registration and doubly labeled water. J Appl Physiol 81:1019-1026 
Campbell WW, Crim MC, Young VR, Evans WJ (1994) Increased energy requirements and changes in body composition with resistance training in older adults. Am J Clin Nutr 55:802-810

De Vito G, Hernandez R, Conzalez V, Felici F, Figura F (1997) Low intensity physical training in older subjects. J Sports Med Phys Fitness 37:72-77

Goran MI, Poehlman ET (1992) Endurance training does not enhance total energy expenditure in healthy elderly persons. Am J Physiol 263:E950-E957

Horber FF, Kohler SA, Lippuner K, Jaeger P (1996) Effect of regular physical training on age-associated alteration of body composition in men. Eur J Clin Invest 26:279-285

Meijer GAL, Janssen GME, Westerterp KR, Verhoeven F, Saris WHM (1991a) The effect of a 5-month endurance-training programme on physical activity: evidence for a sex-difference in the metabolic response to exercise. Eur J Appl Physiol 62:11-17

Meijer GAL, Westerterp KR, Seyts GHP, Janssens GME, Saris WHM, Ten Hoor F (1991b) Body composition and sleeping metabolic rate in response to a 5-month endurance-training programme in adults. Eur J Appl Physiol 62:18-21

Poehlman ET, Gardner AW, Ades PA, Katzman-Rooks SM, Montgomery SM, Atlas OK, Ballor DL, Tyzbir RS (1992) Resting energy metabolism and cardiovascular disease risk in resistance-trained and aerobically trained males. Metabolism 41: $1351-1360$

Posner JD, Gorman KM, Windsor-Lansberg L, Larsen J, Bleiman M, Shaw C, Rosenberg B, Knebl J (1992) Low to moderate intensity endurance training in healthy older adults: physiological responses after four months. J Am Geriatr Soc 40:1-7

Rising R, Harper IT, Fontvielle AM, Ferraro RT, Spraul M, Ravussin E (1994) Determinants of total daily energy expenditure: variability in physical activity. Am J Clin Nutr 59:800-804

Schoffelen PFM, Westerterp KR, Saris WHM, Ten Hoor F (1997) A dual-respiration chamber system with automated calibration. J Appl Physiol 83:2064-2072
Siri WE (1956) The gross composition of the body. Adv Biol Med Phys 4:239-203

Takeshima N, Tanaka K, Kobayashi F, Watanabe T, Kato T (1993) Effects of aerobic exercise conditioning at intensities corresponding to lactate threshold in the elderly. Eur J Appl Physiol 67:138-143

Van Etten LMLA, Westerterp KR, Verstappen FTJ, Boon BJB, Saris WHM (1997) Effect of an 18-week weight-training program on energy expenditure and physical activity. J Appl Physiol 82:298-304

Van Pelt RE, Jones PP, Davy KP, Desouza CA, Tanaka H, Davy BM, Seals DR (1997) Regular physical activity and the agerelated decline in resting metabolic rate in women. $\mathbf{J}$ Clin Endocrinol Metab 82:3208-3212

Van Staveren WA, Deurenberg P, Burema J, De Groot LC, Hautvast JG (1986) Seasonal variations in food intake, pattern of physical activity and changes in body weight in a group of young adult Dutch women consuming self selected diets. Int J Obes 10:133-145

Weir JB (1949) New methods for calculating metabolic rate with special reference to predicting protein metabolism. J Physiol (Lond) 109:1-9

Westerterp KR (1998) Alterations in energy balance with exercise. Am J Clin Nutr 68 [Suppl]:970S-974S

Westerterp KR, Meijer GAL, Janssen EME, Saris WHM, Ten Hoor F (1992) Long term effect of physical activity on energy balance and body composition. Br J Nutr 68:21-30

Westerterp KR, Meijer GAL, Schoffelen P, Janssen EME (1994) Body mass, body composition and sleeping metabolic rate before, during and after endurance training. Eur J Appl Physiol 69:203-208

Wilmore JH, Stanforth PR, Hudspeth LA, Gagnon J, Daw EW, Leon AS, Rao DC, Skinner JS, Bouchard C (1998) Alterations in resting metabolic rate as a consequence of $20 \mathrm{wk}$ of endurance training: the HERITAGE Family study. Am J Clin Nutr 68:66-71 